\title{
INIERE SPACQE \\ ANÁLISE COMPARATIVA DE MÉTODOS DE CLASSIFICAÇÃO SUPERVISIONADA APLICADA AO MAPEAMENTO DA COBERTURA DO SOLO NO MUNICÍPIO DE MEDICILÂNDIA, PARÁ
}

\author{
COMPARATIVE ANALYSIS THE METHODS OF SUPERVISED \\ CLASSIFICATION APPLIED TO THE MAPPING OF SOIL COVER IN THE \\ MUNICIPALITY OF MEDICILÂNDIA, PARÁ \\ ANÁLISIS COMPARATIVO DE MÉTODOS DE CLASIFICACIÓN \\ SUPERVISADA APLICADA AL MAPEO DE LA COBERTURA DEL SUELO \\ EN EL MUNICIPIO DE MEDICILÂNDIA, PARÁ
}

\section{Jones Remo Barbosa Vale}

Mestre em Geografia pela Universidade Federal do Pará - UFPA. Graduado em Geografia pelo Instituto Federal de Educação, Ciência e Tecnologia do Pará - IFPA. Graduando em Engenharia

Cartográfica e de Agrimensura pela Universidade Federal Rural da Amazônia - UFRA. jonesremo@hotmail.com

Jamer Andrade da Costa

Mestre em Engenharia Civil pela Universidade Federal do Pará - UFPA. Professor da Universidade Federal Rural da Amazônia - UFRA. jamer@terra.com.br

\section{Jefferson Ferreira dos Santos}

Graduando em Engenharia Cartográfica e de Agrimensura pela Universidade Federal Rural da Amazônia - UFRA. jefhersonds@gmail.com

Elton Luis Silva da Silva

Graduando em Engenharia Cartográfica e de Agrimensura pela Universidade Federal Rural da Amazônia - UFRA. eltonsylver@gmail.com

Artur Trindade Favacho

Graduando em Engenharia Cartográfica e de Agrimensura pela Universidade Federal Rural da Amazônia - UFRA. arturfavacho41@gmail.com

Recebido para avaliação em 09/11/2017; Aceito para publicação em 26/02/2018.

\section{RESUMO}

As imagens de satélite são produtos gerados por sensoriamento remoto e, estão associadas aos fenômenos e eventos que ocorrem na superfície a partir do registro e da análise das interações entre a radiação eletromagnética e os alvos. O objetivo do trabalho é comparar métodos de classificação supervisionada de imagens de satélite para o mapeamento da cobertura do solo. A área de estudo compreende o município de Medicilândia, localizado no sudoeste paraense. Para a realização do trabalho foram utilizados imagens do satélite Landsat 8, sensor OLI-TIRS, cenas 226/062 e 
|Análise comparativa de métodos de classificação supervisionada aplicada ao mapeamento da cobertura do solo no município de Medicilândia, Pará|

|Jones Remo Barbosa Vale | Jamer Andrade da Costa | Jefferson Ferreira dos Santos | Elton Luis Silva da Silva | Artur Trindade Favacho|

227/062. Foram realizados os testes de classificação, utilizando três classificadores: Distância Mínima, Distância Mahalanobis e Máxima Verossimilhança. Na etapa de classificação foram identificadas as seguintes classes: água, nuvem, sombra de nuvem, solo exposto, vegetação primária e vegetação secundária. Para fins de avaliação da fidedignidade da classificação de cada método foram calculados, o Índice Kappa e a Exatidão Global. A classificação pelo método Máxima Verossimilhança obteve maior exatidão apresentando Índice Kappa de 0,920 e Exatidão Global $96 \%$ quando comparada à classificação pelos métodos Distância Mínima e Distância Mahalanobis, que apresentaram Índice Kappa de 0,842 e 0,845 e Exatidão Global 92\% respectivamente. As técnicas de classificação supervisionada são ferramentas essenciais no processo de mapeamento da cobertura do solo de grandes áreas, visto que dispondo-se de recursos limitados, imagens de baixo custo e de sistemas livres para processamento e integração das informações, é possível obter parâmetros com altos níveis de precisão, sendo fundamentais para subsidiar o planejamento territorial e ambiental.

Palavras-chave: Sensoriamento Remoto; Classificação de Imagens de Satélite; Cobertura do Solo.

\section{ABSTRACT}

The satellite images are products generated by remote sensing and are associated with phenomena and events that occur on the surface from the recording and analysis of interactions between electromagnetic radiation and targets. The objective of this work is to compare methods of supervised classification of satellite images for the mapping of the soil cover. The study area comprises the municipality of Medicilândia, located in southwest of Para. In order to perform the work, were used images from the Landsat 8 satellite, OLI-TIRS sensor, scenes 226/062 and 227/062. The classification tests were performed using three classifiers: Minimum Distance, Mahalanobis Distance and Maximum Likelihood. In the classification processe were identified the following classes: water, cloud, cloud shadow, exposed soil, primary vegetation and secondary vegetation. For the purposes of evaluating the reliability of the classification of each method were calculated, Kappa Index and Global Accuracy. The classification by the Maximum Likelihood method obtained a greater accuracy presenting Kappa Index of 0,920 and Global Accuracy 96\% when compared to the classification by the Minimum Distance and Mahalanobis Distance, which presented Kappa Index of 0,842 and 0,845 and Global Accuracy 92\% respectively. The supervised classification techniques are essential tools in the mapping process of large-area soil cover, since with limited resources, low-cost images and free systems for processing and integrating information, it is possible to obtain parameters with high levels of precision, being fundamental to subsidize territorial and environmental planning.

Keywords: Remote Sensing; Classification of Satellite Images; Soil Cover.

\section{RESUMEN}

Las imágenes de satélite son productos generados por la detección remota y están asociados a los fenómenos y eventos que ocurren en la superficie a partir del registro y del análisis de las interacciones entre la radiación electromagnética y los blancos. El objetivo del trabajo es comparar métodos de clasificación supervisada de imágenes de satélite para el mapeo de la cobertura del suelo. El área de estudio comprende el municipio de Medicilândia, ubicado en el suroeste paraense. Para la realización del trabajo se utilizaron imágenes del satélite Landsat 8, sensor OLI-TIRS, escenas 226/062 y 227/062. Se utilizaron tres clasificadores: Distancia Mínima, Distancia Mahalanobis y Máxima Verosimilitud. En la etapa de clasificación se identificaron las siguientes clases: agua, nube, sombra de nube, suelo expuesto, vegetación primaria y vegetación secundaria. Para evaluar la confianza de la clasificación de cada método se ha calculado, el Índice Kappa y la Exactitud Global. La clasificación por Máxima Verosimilitud obtuvo mayor exactitud presentando Índice Kappa de 0,920 y Exactitud Global 96\% cuando comparada a la clasificación por Distancia Mínima y Distancia Mahalanobis, que presentaron Índice Kappa de 0,842 y 0,845 y Exactitud Global 92\% respectivamente. Las técnicas de clasificación supervisada son herramientas esenciales en el proceso de mapeo de la cobertura del suelo de grandes áreas, ya que disponiendo de recursos limitados, imágenes de bajo costo y de sistemas libres para procesamiento e integración de la 
|Análise comparativa de métodos de classificação supervisionada aplicada ao mapeamento da cobertura do solo no município de Medicilândia, Pará|

|Jones Remo Barbosa Vale | Jamer Andrade da Costa | Jefferson Ferreira dos Santos | Elton Luis Silva da Silva | Artur Trindade Favacho|

información, es posible obtener parámetros con altos niveles de precisión, siendo fundamentales para subsidiar la planificación territorial y ambiental.

Palabras clave: Sensoramiento Remoto; Clasificación de Imágenes de Satélite; Cobertura del Suelo.

\section{INTRODUÇÃO}

O Sensoriamento Remoto constitui a utilização conjunta de sensores, equipamentos para processamento de dados, equipamentos de transmissão de dados colocados a bordo de aeronaves, espaçonaves ou outras plataformas com o objetivo de estudar fenômenos, eventos e processos que ocorrem na superfície do planeta Terra a partir do registro e da análise das interações entre a radiação eletromagnética e as substâncias que a compõem em suas mais diversas manifestações (NOVO, 2010).

Através de softwares dedicados ao tratamento de imagens obtidas à distância pelos sensores remotos acoplados em satélites, é possível obter muitas informações sobre os ambientes da superfície terrestre e gerar mapas temáticos como os de geologia, hidrografia, solos, relevo, vegetação e uso da terra (FLORENZANO, 2008).

De acordo Fonseca (2000), o uso de imagens de satélite como fonte de informação para a produção de mapas, é um dos grandes impulsionadores de inovações no ramo do geoprocessamento. Segundo Rosa (2013), o geoprocessamento é um conjunto de tecnologias destinadas à coleta e tratamento de informações espaciais, assim como o desenvolvimento de novos sistemas e aplicações, com diferentes níveis de sofisticação. Fitz (2008) destaca que o geoprocessamento utiliza um Sistema de Informações Geográficas (SIG) para realizar levantamentos e análises de informações georreferenciadas para planejar e/ou gerenciar um espaço específico.

O desenvolvimento de tecnologias, métodos e técnicas permitiram o avanço na obtenção de dados da superfície terrestre e, com isso, houve redução do tempo gasto em trabalhos de campo e possibilitou a obtenção de informações em locais de difícil acesso (ANDRADE et al., 2014).

A partir dos dados oriundos das geotecnologias surgiram diversas metodologias e dentre elas uma no que diz respeito à elaboração de mapas, principalmente, no que tange a classificação de imagens de satélite. O processamento de imagens digitais visa fornecer ferramentas para facilitar a identificação e a extração das informações contidas nas imagens, para posterior interpretação. Assim, o fundamento deste processo refere-se a um conjunto de medições de radiância obtidas em diferentes faixas do espectro eletromagnético. Desta 
|Análise comparativa de métodos de classificação supervisionada aplicada ao mapeamento da cobertura do solo no município de Medicilândia, Pará|

|Jones Remo Barbosa Vale | Jamer Andrade da Costa | Jefferson Ferreira dos Santos | Elton Luis Silva da Silva | Artur Trindade Favacho |

forma são associados valores numéricos a cada pixel da imagem, que descrevem um objeto real da superfície terrestre (CRÓSTA, 2002; JENSEN, 2009; LILLESAND; KIEFER; CHIPMAN, 2008).

Nesse sentido, sistemas dedicados de computação são utilizados para atividades interativas de análise e manipulação das imagens brutas. O resultado desse processo é a produção de outras imagens, estas já contendo informações específicas, extraídas e realçadas a partir das imagens brutas (CRÓSTA, 2002). De acordo com Queiroz et al. (2004), existem vários métodos de classificação que buscam, através de diversas abordagens, identificar com acurácia a informação de cada pixel da imagem, classificando-o em categorias.

Segundo Campbell (1996), o processo de classificação supervisionada das imagens apresenta vantagens e desvantagens. A principal vantagem é que o analista tem maior controle sobre o processo, como por exemplo, pré-definir classes e identificar possíveis imprecisões graves pela análise das áreas de treinamento. A principal desvantagem é que o analista impõe uma determinada estrutura de classificação aos dados, através da definição prévia das classes de informação. Estas classes podem não corresponder às classes reais existentes na cena imageada, ou não ser separáveis no espaço dimensionado.

A classificação supervisionada se baseia na identificação de diferentes classes com comportamentos espectrais diferenciados. Para isso, algoritmos de classificação são adotados para extrair as feições de interesse em um espaço multidimensional (BERNARDI, 2007). Os algoritmos de classificação supervisionada são: Distância Mínima, Distância Mahalanobis, Distância de Bhattacharya, Máxima Verossimilhança, Método Paralelepípedo e Método Spectral Angle Mapper (AMARAL et al., 2009; CORREIA et al., 2007; CRÓSTA, 2002; RIBEIRO et al., 2007; VIEIRA JUNIOR, 2011; ZANETTI et al., 2017).

O objetivo do trabalho foi comparar três métodos de classificação supervisionada (Distância Mínima, Distância Mahalanobis e Máxima Verossimilhança), a fim de se verificar qual método oferece melhores resultados para o mapeamento da cobertura do solo do município de Medicilândia, sudoeste paraense.

\section{APORTE TEÓRICO-METODOLÓGICO}

\section{Fundamentos Teóricos}


|Análise comparativa de métodos de classificação supervisionada aplicada ao mapeamento da cobertura do solo no município de Medicilândia, Pará|

|Jones Remo Barbosa Vale | Jamer Andrade da Costa | Jefferson Ferreira dos Santos | Elton Luis Silva da Silva | Artur Trindade Favacho|

O conhecimento do espaço é extrema importância para planejadores e legisladores, pois, ao verificar a utilização do solo em determinada área, pode-se elaborar uma melhor política de uso da terra para o desenvolvimento ordenado da região (BRITO; PRUDENTE, 2005). A classificação é o processo de extração de informação em imagens para reconhecer padrões e objetos homogêneos e são utilizados em sensoriamento remoto para mapear áreas da superfície terrestre que correspondem aos temas de interesse (CAMARA et al., 1996).

A classificação de imagens de satélite se apresenta como um diferencial, pois o principal objetivo dos procedimentos é classificar automaticamente todos os pixels de uma imagem em classes de cobertura do solo (LILLESAND; KIEFER; CHIPMAN, 2008). Desta forma, o uso de métodos estatísticos vinculados à busca de padrões espaciais e outras técnicas favorecem a automação do processo de extração de informações.

Segundo Meneses e Almeida (2002), os diversos métodos de classificação em uso podem ser divididos segundo diferentes critérios, tais como:

(...) Classificação paramétrica e não-paramétrica, classificação espectral e espacial, e classificação supervisionada ou não-supervisionada. Há ainda a possibilidade de dividir os classificadores em classificação por pixel ou por regiões. A maioria dos classificadores executa a classificação por pixel, que se utiliza somente da informação espectral de cada pixel para encontrar regiões homogêneas, a partir de medidas de distâncias ou de probabilidades de um pixel pertencer a uma classe específica (MENESES; ALMEIDA, 2012, p. 191).

Aparentemente, o processo de classificação dos alvos presentes na imagem é uma questão simples. No entanto, há uma série de fatores que podem interferir nesse processo. Portanto, a classificação de imagens deve ser vista como um processo estatístico e probabilístico que tenta ao máximo aproximar o mapa digital à realidade. O resultado da classificação deve ser avaliado com base no desempenho do classificador proposto e validado por critérios numéricos para estimar a precisão e a sua acurácia (MENESES; ALMEIDA, 2002).

Para realizar a classificação são utilizados modelos matemáticos denominados algoritmos. Eles são divididos em função da presença ou não de uma fase de treinamento, pela qual o usuário fornece amostras referentes a pixels representativos para cada uma das classes de interesse. Assim, os softwares comerciais de processamento de imagens de sensoriamento remoto separam os classificadores em não-supervisionados $\mathrm{e}$ supervisionados.

A classificação não-supervisionada requer pouca ou nenhuma participação do analista no processo de classificação da imagem, pois a classificação é quase que totalmente 
|Análise comparativa de métodos de classificação supervisionada aplicada ao mapeamento da cobertura do solo no município de Medicilândia, Pará|

|Jones Remo Barbosa Vale | Jamer Andrade da Costa | Jefferson Ferreira dos Santos | Elton Luis Silva da Silva | Artur Trindade Favacho|

automatizado pelo computador. Neste tipo de classificação o analista especifica alguns parâmetros que o computador irá usar para descobrir padrões que são inerentes aos dados. Há dois principais algoritmos de classificação não-supervisionada de amplo uso, Isodata e K-Means, ambos se baseiam no agrupamento de pixels por suas similaridades (MENESES; ALMEIDA, 2002).

A classificação supervisionada requer que o analista tenha um conhecimento prévio das classes presentes na imagem. Em tal abordagem, o analista treina o algoritmo para poder distinguir as classes uma das outras, baseando-se em regras estatísticas préestabelecidas (VENTURIERI, 2007). Uma área da imagem que o analista identifica como representando uma das classes é chamada de área de treinamento. De acordo com Crósta (2002), uma área de treinamento é:

(...) Definida pelo usuário traçando-se seus limites diretamente sobre a imagem, no monitor de vídeo do sistema de processamento de imagens. Várias áreas de treinamento podem ser definidas para uma mesma classe, para assegurar que os pixels a ela pertencentes são realmente representativos dessa classe. Todos os pixels dentro de uma área de treinamento para uma dada classe constituem o chamado conjunto de treinamento para aquela classe (CRÓSTA, 2002, p. 115).

Não há nenhuma restrição quanto ao número de classes a serem classificadas, apenas que o analista faça uma seleção de classes bem distintas porque, caso contrário, no final da classificação ocorrerá muita confusão entre as classes (RODRIGUES, 2015). Há vários métodos de classificação supervisionada, dentre eles: Distância Mínima, Distância Mahalanobis e Máxima Verossimilhança.

O método da distância mínima calcula a distância espectral entre o vetor de medida para o pixel candidato e a média para cada assinatura de classe. O método se utiliza da medida de distância Euclidiana. Cada pixel será incorporado a um agrupamento através da análise da medida de similaridade de distância Euclidiana, que é dada por:

$$
\mathrm{D}(\mathrm{x}, \mathrm{n})=\sqrt{\left(\mathrm{x}_{\mathrm{i}}-\mathrm{m}_{\mathrm{i}}\right)^{2}}
$$

onde xi é pixel candidato, mi é a média das classes e n é o número de bandas. $\mathrm{O}$ classificador compara a distância Euclidiana de cada pixel à média de cada agrupamento. $\mathrm{O}$ pixel candidato é designado à classe com média mais próxima, isto é, à classe que apresenta a menor distância Euclidiana (MENESES; ALMEIDA, 2002).

O método distância Mahalanobis é, simplesmente, a medida da distância do pixel na posição x do espaço multidimensional ao centro da classe, dividida pelo comprimento do 
|Análise comparativa de métodos de classificação supervisionada aplicada ao mapeamento da cobertura do solo no município de Medicilândia, Pará|

|Jones Remo Barbosa Vale | Jamer Andrade da Costa | Jefferson Ferreira dos Santos | Elton Luis Silva da Silva | Artur Trindade Favacho |

elipsóide na direção de x. Isso tem a propriedade de minimizar a distância do ponto ao centro de média (MENESES; ALMEIDA, 2002).

Para se usar a distância Mahalanobis para classificar um pixel a uma das $n$ classes, inicialmente, calcula-se a matriz de covariância com base nas amostras de treinamento das n classes, e o pixel será destinado à classe na qual a distância de Mahalanobis seja a menor de todas. Esse método supõe que a covariância das amostras são iguais, portanto, é um algoritmo mais rápido que os algoritmos de distância mínima e o máxima verossimilhança (RICHARDS; JIA, 2006). A classificação ocorre por:

$$
D_{m}(x, y)=|x-y| A=\sqrt{(x-y)^{T} A^{-1}(x-y)}
$$

onde $\mathrm{D}_{\mathrm{m}}(\mathrm{x}, \mathrm{y})$ é a distância entre dados dois vetores de cores (x e y) e $\mathrm{A}^{-1}$ é a matriz de covariância inversa computada a partir de uma distribuição multivariada de entrada (neste caso, os padrões de pele). Como pode ser observado, a equação acima também se reduz à norma vetorial, caso A seja uma matriz identidade.

O método máxima verossimilhança (MaxVer) considera a ponderação das distâncias entre as médias dos valores dos pixels das classes, utilizando parâmetros estatísticos. Assume que todas as bandas têm distribuição normal e calcula a probabilidade de um dado pixel pertencer a uma classe específica (INPE, 2008). Para que a classificação por MaxVer seja precisa, é necessário um número razoavelmente elevado de pixels para cada conjunto de treinamento, esse número permite uma base segura para tratamento estatístico (CRÓSTA, 2002).

$\mathrm{Na}$ classificação MaxVer cada pixel é destinado à classe que tem a mais alta probabilidade, isto é, a máxima verossimilhança. Isso significa que para um pixel na posição $\mathrm{x}$ do espaço multiespectral, um conjunto de probabilidades são computadas e que dão as possibilidades relativas do pixel pertencer a cada classe disponível $(\mathrm{p}(\mathrm{x} \mid \omega \mathrm{\omega}))$. Segundo Richard e Jia, (2006) a classificação de um ponto x é realizada de acordo com:

$$
x \in w_{i} \operatorname{sep}\left(x / w_{i}\right) p\left(w_{i}\right)>p\left(x / w_{j}\right) p\left(w_{j}\right)
$$

onde, a probabilidade $\mathrm{p}(\mathrm{x} / \omega \mathrm{i})$ dá a possibilidade de $\mathrm{x}$ pertencer à classe $\omega \mathrm{i}$ e $\mathrm{p}(\omega \mathrm{i})$ é a probabilidade de a classe ocorrer na imagem, que de fato é conhecida das áreas de treinamento. Tantas quanto forem as classes de treinamento selecionadas, tantas serão $\mathrm{p}(\mathrm{x} / \omega \mathrm{i})$. 
|Análise comparativa de métodos de classificação supervisionada aplicada ao mapeamento da cobertura do solo no município de Medicilândia, Pará|

|Jones Remo Barbosa Vale | Jamer Andrade da Costa | Jefferson Ferreira dos Santos | Elton Luis Silva da Silva | Artur Trindade Favacho |

O MaxVer tem uma base estatística mais complexa e por isso utiliza um tempo bem maior de computação do que os dois demais métodos. Como suas premissas estatísticas são das áreas de treinamento e, se o analista por algum motivo não consegue definir áreas de treinamento bastante representativas, corre o perigo de que a imagem classificada contenha muitas imprecisões (MENESES e ALMEIDA, 2002).

\section{Área de Estudo}

O município de Medicilândia (Figura 1) localiza-se na mesorregião sudoeste paraense e na microrregião de Altamira, distante a $915 \mathrm{~km}$ de Belém e $90 \mathrm{~km}$ do município de Altamira. A sua área territorial é equivalente a $8.272,6 \mathrm{~km}^{2}$, apresentando uma densidade demográfica de 3,30 habitantes por $\mathrm{km}^{2}$ (VALENTE, 2012).

Inicialmente, Medicilândia era uma agrovila instalada no Km 90 da Rodovia Transamazônica (BR-230) e teve sua origem relacionada com o Programa de Integração Nacional (PIN), instituído pelo Governo Federal através do Instituto Nacional de Colonização e Reforma Agrária (INCRA) no ano de 1970 e implantado a partir de 1971 com o objetivo de desenvolver um grande Programa de Colonização e Reforma Agrária dirigida na Amazônia, trazendo trabalhadores sem-terra de diversas regiões do Brasil (VALENTE, 2012). 
|Análise comparativa de métodos de classificação supervisionada aplicada ao mapeamento da cobertura do solo no município de Medicilândia, Pará|

|Jones Remo Barbosa Vale | Jamer Andrade da Costa | Jefferson Ferreira dos Santos | Elton Luis Silva da Silva | Artur Trindade Favacho|

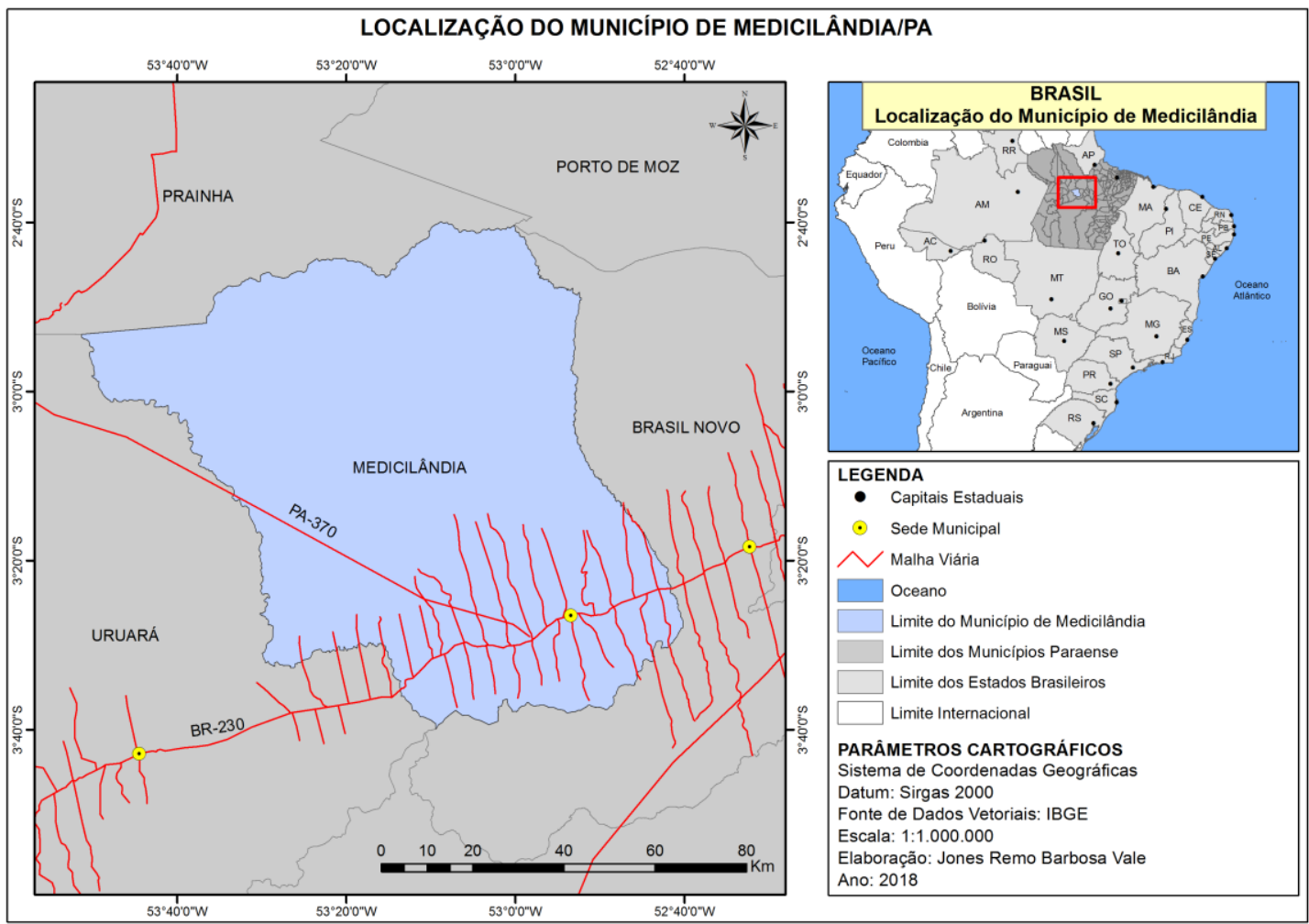

Figura 1 - Mapa de localização geográfica do município de Medicilândia, sudoeste paraense Fonte: IBGE.

A transformação da agrovila em município se deu em função de vários fatores, dentre os quais, o destaque foi à fertilidade dos solos locais, que resultou no dinamismo do setor agrícola na localidade. Atualmente, o município é caracterizado pela predominância da população residindo em zona rural. De acordo com o censo demográfico de 2010 a população era de 27.328 habitantes, sendo 17.769 habitantes, aproximadamente 65\% da população residindo na zona rural e 9.559 habitantes, aproximadamente $35 \%$ da população residindo na zona urbana (IBGE, 2010).

Nos últimos anos a lavoura cacaueira vem sendo destaque pelo crescimento de sua produção e geração de emprego, o que acaba aquecendo a economia local (FVPP, 2010). A agropecuária corresponde a 38,3\% do PIB do município, tendo o cacau como principal cultura, representando aproximadamente $73 \%$ do valor correspondente à agropecuária. Além da grande expressão econômica do cacau, a produção de café e banana também são destaques no município (VALENTE, 2012).

\section{Materiais Utilizados}


|Análise comparativa de métodos de classificação supervisionada aplicada ao mapeamento da cobertura do solo no município de Medicilândia, Pará|

|Jones Remo Barbosa Vale | Jamer Andrade da Costa | Jefferson Ferreira dos Santos | Elton Luis Silva da Silva | Artur Trindade Favacho |

Foram utilizadas para o desenvolvimento deste trabalho as imagens de satélite do Landsat 8 /sensor OLI-TIRS, cenas 226/062 e 227/062, disponibilizadas gratuitamente pela United States Geological Survey (USGS). Os metadados das imagens podem ser visualizados no Quadro 1.

Quadro 1 - Metadados das Imagens do Satélite Landsat 8

\begin{tabular}{|c|c|c|c|c|}
\hline SENSOR & $\begin{array}{c}\text { RESOLUÇÃO } \\
\text { ESPECTRAL }\end{array}$ & $\begin{array}{c}\text { RESOLUÇÃO } \\
\text { RADIOMÉTRICA }\end{array}$ & ANO & $\begin{array}{c}\text { COMPOSIÇÃO } \\
\text { COLORIDA }\end{array}$ \\
\hline OLI-TIRS & $30 \mathrm{~m}$ & 16 bits convertidas em 8 bits & 2016 & 6R5G4B \\
\hline
\end{tabular}

Os procedimentos de pré-processamento e processamento de imagens foram executados no software ENVI 4.7, enquanto que a edição final dos mapas e verificação da qualidade das classificações foi realizada no software QGIS 2.18.

\section{Procedimentos Metodológicos}

Após a aquisição das imagens do satélite Landsat 8, foi iniciada a etapa de préprocessamento que refere-se ao tratamento inicial dos dados brutos obtidos pelo sistema sensor, de modo a remover características indesejáveis produzidas na imagem. Segundo Meneses e Almeida (2012), o pré-processamento tem a função de preparar para o analista uma imagem de alto contraste visual, para facilitar a interpretação da cena, poder explorar com melhores recursos toda a informação contida na imagem e extrair informações de interesse e/ou relacioná-las com parâmetros estatísticos, num processo que objetiva aperfeiçoar ao máximo a análise dos dados, em termos de eficiência, tempo e custo.

De acordo com Venturieri (2007), as técnicas de pré-processamento podem ser agrupadas em três tipos de correção denominadas de atmosférica, radiométrica e geométrica. A correção da imagem depende dos objetivos do trabalho ou da pesquisa que o analista propôs fazer, podendo iniciar por qualquer uma delas.

Neste trabalho aplicou-se a correção atmosférica pelo algoritmo Fast Line-of-sight Atmospheric Analysis of Hypercubes (FLAASH), que se baseia no Modelo de Transferência Radioativa (MODTRAN). A correção dos efeitos atmosféricos é realizada de acordo com a equação:

$$
L=\left(\frac{A \rho}{1-\rho e S}\right)+\left(\frac{B \rho e}{1-\rho e S}\right)+L a
$$


|Análise comparativa de métodos de classificação supervisionada aplicada ao mapeamento da cobertura do solo no município de Medicilândia, Pará|

|Jones Remo Barbosa Vale | Jamer Andrade da Costa | Jefferson Ferreira dos Santos | Elton Luis Silva da Silva | Artur Trindade Favacho|

onde $\mathrm{L}$ é a radiância no sensor, $\rho$ é a reflectância de superfície do pixel, $\rho e$ é a média da reflectância de superfície do pixel e da região vizinha, S é o albedo esférico da atmosfera, é a radiância retroespalhada na atmosfera e A e B são parâmetros que dependem das condições da atmosfera e da geometria de iluminação (COOLEY et al., 2002; ADLERGOLDEN et al., 1999; ANDERSON et al., 1999). O MODTRAN é capaz de estimar os valores de A, B, S e La para uma dada condição atmosférica e assim determinar a radiância da superfície e em seguida, a reflectância.

Em seguida, foi iniciada a etapa de processamento da imagem. Primeiro houve a moisacagem das duas cenas e, por conseguinte o recorte no limite do município. Utilizando a composição de imagem falsa cor RGB-654, a partir de padrões de cores, texturas e formas, fez-se a classificação pelos métodos de: Distância Mínima, Distância Mahalanobis e Máxima Verossimilhança. Para todos os métodos foram geradas as classes: água, nuvem, sombra de nuvem, solo exposto, vegetação primária e vegetação secundária. As características de cada classe podem ser observadas no Quadro 2.

Quadro 2-Características das classes mapeadas

\begin{tabular}{|c|l|}
\hline CLASSE & \multicolumn{1}{|c|}{ CARACTERÍSTICA } \\
\hline Água & $\begin{array}{l}\text { Nesta classe foi incluída toda e qualquer área que apresente exposição de } \\
\text { corpos d'água possíveis de observação, tais como: rios, lagos e igarapés. }\end{array}$ \\
\hline Nuvem & $\begin{array}{l}\text { Nesta classe foi detectada nuvens de baixa altitude, tais como, Cumulus e } \\
\text { Stratocumulus, que ocupam pequenas áreas. }\end{array}$ \\
\hline Sombra de Nuvem & $\begin{array}{l}\text { Nesta classe foi detectada a sombra de nuvens de baixa altitude, tais } \\
\text { como, Cumulus e Stratocumulus, que apresentam sombras possíveis de } \\
\text { detectar e ocupam pequenas áreas. }\end{array}$ \\
\hline Solo Exposto & $\begin{array}{l}\text { Nesta classe foram incluídas as áreas entendidas como antropizadas (áreas } \\
\text { residenciais, estradas pavimentadas e não-pavimentadas). Além de áreas } \\
\text { desflorestadas devido à implantação de atividades agropecuárias ou } \\
\text { exploração florestal. }\end{array}$ \\
\hline Vegetação Primária & $\begin{array}{l}\text { Nesta classe foram incluídas formações de florestas pioneiras da } \\
\text { Amazônia oriental, onde é característica, a presença de árvores de porte } \\
\text { elevado que chegam a atingir 40m de altura. Também foi classificada a } \\
\text { vegetação que ocorre ao longo dos rios (floresta ombrófila densa aluvial). }\end{array}$ \\
\hline Vegetação Secundária & $\begin{array}{l}\text { Nesta classe foram incluídas áreas que depois de ter sofrido uma } \\
\text { supressão total de sua vegetação original, está em processo de regeneração } \\
\text { do tipo arbóreo-arbustiva. Segundo Lamprecht (1990), a vegetação } \\
\text { secundária é mais jovem, constitui-se de estrutura mais simples e, } \\
\text { consideravelmente, mais pobre em espécies comparado a vegetação } \\
\text { primária condicionada por uma mesma situação de sitio. Também foi } \\
\text { incluída a vegetação dominada por espécies forrageiras, subarbusto e } \\
\text { herbáceas invasores. }\end{array}$ \\
\hline
\end{tabular}


|Análise comparativa de métodos de classificação supervisionada aplicada ao mapeamento da cobertura do solo no município de Medicilândia, Pará|

|Jones Remo Barbosa Vale | Jamer Andrade da Costa | Jefferson Ferreira dos Santos | Elton Luis Silva da Silva | Artur Trindade Favacho |

O propósito do trabalho foi o de classificar o mapeamento da cobertura do solo, no entanto, classificou-se nuvem e sombra de nuvem devido à permanência mesmo após a etapa de pré-processamento da imagem. Entretanto, não houve comprometimento da classificação da cobertura do solo, pois essas duas classes representam uma pequena porcentagem na imagem e não atrapalha uma boa interpretação dos alvos pelos classificadores.

Para avaliar o desempenho dos classificadores, adotou-se a metodologia chamada de painel amostral que caracteriza-se pela distribuição aleatória de pontos amostrais dentro do limite do município, com o objetivo de se realizar um levantamento da classe de cada ponto. No software QGIS 2.18 foram gerados 50 pontos amostrais espalhados de forma aleatória na imagem, servindo esses de referência terrestre. A avaliação dos pontos para se determinar a qual classe eles eram pertencentes, foi realizada por inspeção visual. A partir da matriz de confusão (CONGALTON, 1991), foram calculados, o Índice Kappa e a Exatidão Global.

Segundo Cohen (1960), o Índice Kappa é uma medida de concordância que fornece uma ideia do quanto às observações se afastam daquelas esperadas, fruto do acaso, indicando-nos assim o quão legítimo são as interpretações, é calculado com base em uma matriz de erros e, é utilizado como medida de concordância entre o mapa e a referência adotada para a estimativa da exatidão. O cálculo do índice Kappa é expresso por:

$$
\mathrm{K}=\frac{\left[\mathrm{n} * \sum_{\mathrm{i}=1}^{\mathrm{r}} \mathrm{x}_{\mathrm{ij}}-\sum_{\mathrm{i}=1}^{\mathrm{r}}\left(\mathrm{x}_{\mathrm{i}} * \mathrm{x}_{\mathrm{j}}\right)\right]}{\left[\mathrm{n}^{2}-\sum_{\mathrm{i}=1}^{\mathrm{r}}\left(\mathrm{x}_{\mathrm{i}} * \mathrm{x}_{\mathrm{j}}\right)\right]}
$$

onde $\mathrm{K}$ é o Índice de exatidão Kappa, r é o número de linhas na matriz, $\mathrm{x}_{\mathrm{ij}}$ é o número de observações na linha (i) e coluna(j), e n é o número total de observações. A partir dos resultados, Landis e Koch (1977) associam valores do Índice Kappa à qualidade da classificação de acordo com o Quadro 3.

Quadro 3 - Qualidade da classificação associada aos valores do Índice Kappa

\begin{tabular}{|c|c|}
\hline ÍNDICE KAPPA & QUALIDADE \\
\hline 0,00 & Péssima \\
\hline 0,01 a 0,20 & Ruim \\
\hline 0,21 a 0,40 & Razoável \\
\hline 0,41 a 0,60 & Boa \\
\hline 0,61 a 0,80 & Muito boa \\
\hline 0,81 a 1,00 & Excelente \\
\hline
\end{tabular}

Fonte: LANDIS; KOCH, 1977. 
|Análise comparativa de métodos de classificação supervisionada aplicada ao mapeamento da cobertura do solo no município de Medicilândia, Pará|

|Jones Remo Barbosa Vale | Jamer Andrade da Costa | Jefferson Ferreira dos Santos | Elton Luis Silva da Silva | Artur Trindade Favacho |

A Exatidão Global é a medida mais simples de verificação e relaciona os elementos da diagonal com o total de pontos amostrados da imagem classificada, sendo dada pela fórmula:

$$
\mathrm{EG}=\frac{\mathrm{A}}{\mathrm{n}} * 100
$$

onde EG é a Exatidão Global, A é o numero de pontos amostrais com acerto, e n é o número de pontos amostrais.

Segundo Brites (1996), o índice global superestima a classificação e sempre resultará em valores mais altos do que os outros índices. O Índice Kappa, ao calcular a concordância casual, inclui os elementos da diagonal principal, fazendo com que esta concordância seja superestimada, reduzindo o valor do índice.

\section{RESULTADOS E DISCUSSÕES}

O mapeamento da cobertura do solo do município de Medicilândia foi obtido a partir da classificação de imagens do satélite Landsat 8 do ano de 2016. As Figuras 2, 3 e 4 mostram os mapas temáticos com os respectivos resultados das classificações supervisionadas por: Distância Mínima, Distância de Mahalanobis e Máxima Verossimilhança. A Tabela 1 é o percentual de cada classe mapeada em cada método. 
|Jones Remo Barbosa Vale | Jamer Andrade da Costa | Jefferson Ferreira dos Santos | Elton Luis Silva da Silva | Artur Trindade Favacho |

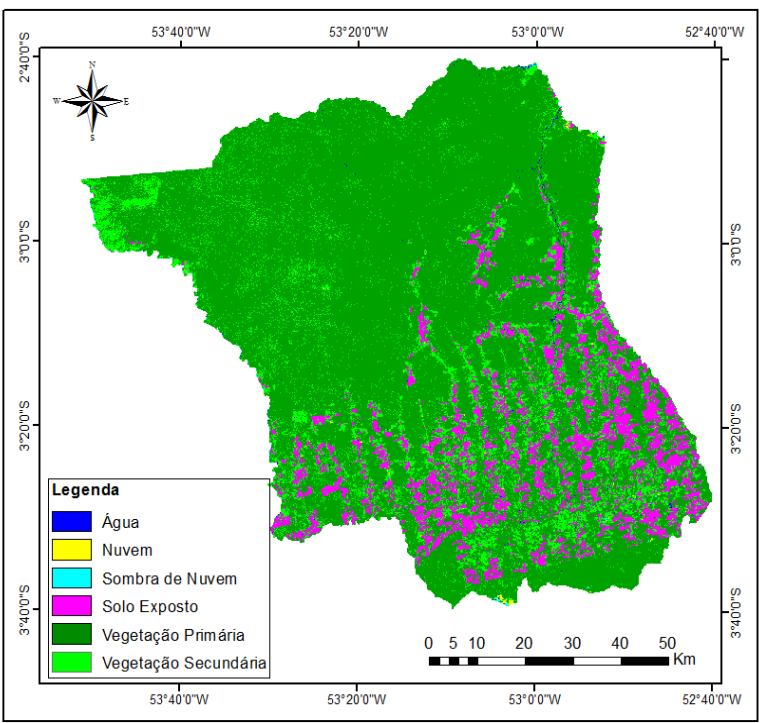

Figura 2 - Mapa da classificação supervisionada pelo método Distância Mínima

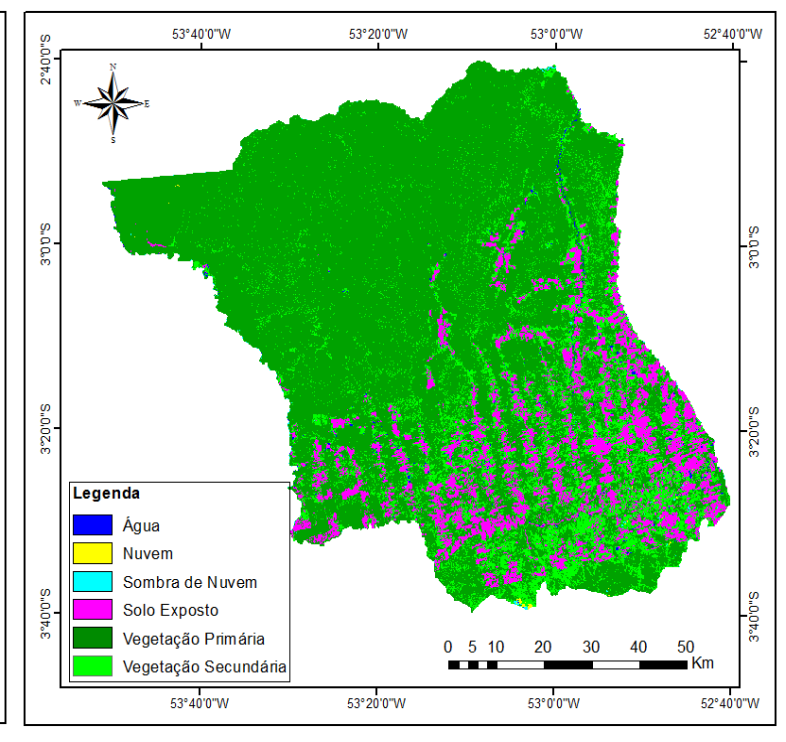

Figura 3 - Mapa da classificação supervisionada pelo método Distância Mahalanobis

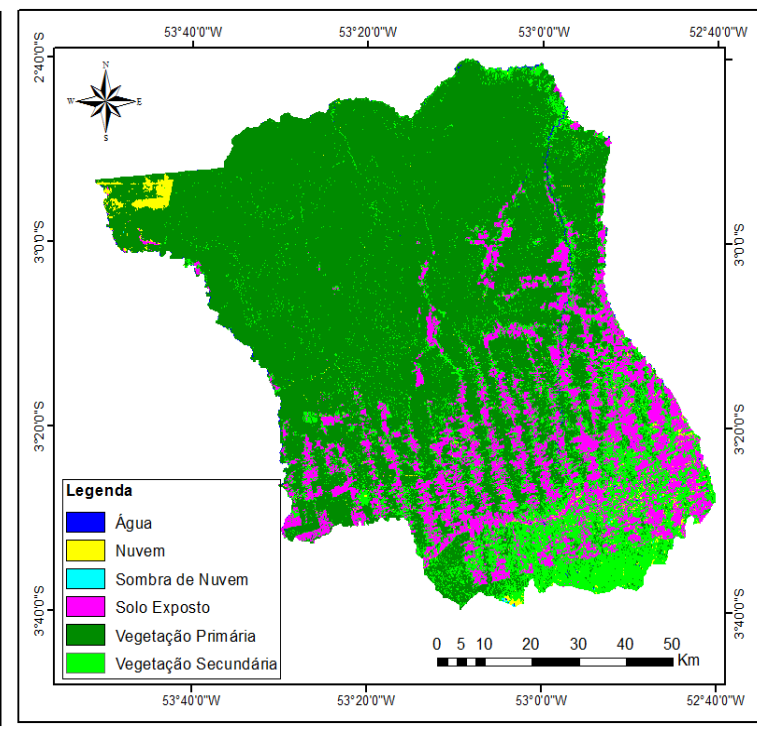

Figura 4 - Mapa da classificação supervisionada pelo método Máxima Verossimilhança

Tabela 1 - Percentual de cada classe

\begin{tabular}{c|c|c|c}
\hline CLASSE & $\begin{array}{c}\text { DISTÂNCIA } \\
\text { MÍNIMA }\end{array}$ & $\begin{array}{c}\text { DISTÂNCIA } \\
\text { MAHALANOBIS }\end{array}$ & $\begin{array}{c}\text { MÁXIMA } \\
\text { VEROSSIMILHANÇA }\end{array}$ \\
\hline Água & 0,375 & 0,220 & 0,160 \\
\hline Nuvem & 0,067 & 0,023 & 0,586 \\
\hline Sombra de Nuvem & 0,048 & 0,075 & 0,013 \\
\hline Solo Exposto & 5,5618 & 6,200 & 8,160 \\
\hline Vegetação Primária & 43,629 & 41,253 & 38,490 \\
\hline Vegetação Secundária & 7,183 & 9,092 & 9,454 \\
\hline Background & 43,137 & 43,137 & 43,137 \\
\hline
\end{tabular}

\begin{tabular}{|llllll|}
\hline InterEspaço & Grajaú/MA & v. 4, n. 13 & p. 26-44 jan./abr. 2018 & Página 39 \\
\hline
\end{tabular}


|Análise comparativa de métodos de classificação supervisionada aplicada ao mapeamento da cobertura do solo no município de Medicilândia, Pará|

|Jones Remo Barbosa Vale | Jamer Andrade da Costa | Jefferson Ferreira dos Santos | Elton Luis Silva da Silva | Artur Trindade Favacho|

A comparação dos dados da Tabela 1 e a visual entre as três classificações (Figuras 2, 3 e 4) e a imagem original mostrou que a classificação por MaxVer apresentou melhor identificação das classes, obtendo uma melhor separação entre as mesmas.

A classe nuvem e sombra de nuvem que são elementos presentes na imagem original, foi melhor identificada pelo algoritmo MaxVer, o mapeamento dessas duas classes tem influência direta em outras classes, pois a não identificação delas ocasiona no agrupamento dessas áreas em outras classes. Pelo método distância mínima essas classes foram classificadas como vegetação secundária e, pelo método de distância mahalanobis como vegetação primária.

A classe solo exposto foi melhor identificada pelo algoritmo MaxVer do que os demais algoritmos analisados, ou seja, conseguiu identificar as extensas áreas antropizadas do município, principalmente as áreas desflorestadas devido à implantação de atividades agropecuárias ou de exploração florestal e, as áreas destinadas a implementação de infraestrutura como construção de estradas.

Após as classificações foram conferidas a precisão de cada método de classificação supervisionada por meio de indicadores estatísticos, como o Índice Kappa e da Exatidão Global. Na Tabela 2, podem ser visualizados os resultados obtidos para os métodos de classificação em cada parâmetro de verificação.

Tabela 2 - Valores obtidos pelo Índice Kappa e pela Exatidão Global

\begin{tabular}{c|c|c}
\hline MÉTODO & ÍNDICE KAPPA (0 a 1) & EXATIDÃO GLOBAL (\%) \\
\hline Distância Mínima & 0,842 & 92 \\
\hline Distância Mahalanobis & 0,845 & 92 \\
\hline Máxima Verossimilhança & 0,920 & 96 \\
\hline
\end{tabular}

Apesar dos três métodos apresentarem valores elevados, tanto no Índice Kappa, como na Exatidão Global, conforme a Tabela 2 o resultado obtido por meio da classificação MaxVer apresentou valores comparativamente mais elevados, ratificando a análise visual. Os métodos de distância mínima e distância mahalanobis apresentaram resultados de precisão bastante elevados e muito próximos, mas abaixo do método MaxVer. Ressalta-se que todas as classificações foram consideradas excelentes de acordo com o Quadro 3. Os excelentes resultados apresentados na Tabela 2 se deram em virtude do cuidado na etapa de pré-processamento e principalmente na etapa de selecionar a área de treinamento. 
|Análise comparativa de métodos de classificação supervisionada aplicada ao mapeamento da cobertura do solo no município de Medicilândia, Pará|

|Jones Remo Barbosa Vale | Jamer Andrade da Costa | Jefferson Ferreira dos Santos | Elton Luis Silva da Silva | Artur Trindade Favacho |

\section{CONSIDERAÇÕES FINAIS}

O uso de instrumentos de sensoriamento remoto é um forte aliado para o conhecimento da superfície terrestre. A associação deste com bancos de dados populacionais, como os censos demográficos, e os naturais, como pedológicos e geológicos, permitem o conhecimento do perfil local e possíveis tendências. Sendo que estas análises podem ser executadas com imagens e SIGs gratuitos, obtendo-se uma redução do tempo e custo do trabalho, permitindo o acompanhamento da evolução física, ambiental e social.

A utilização de métodos de classificação de imagens de satélite tem sido abordada em diversos estudos. O desenvolvimento deste trabalho consistiu em aplicar os métodos de Distância Mínima, Distância de Mahalanobis e Máxima Verossimilhança para classificar a cobertura do solo do município de Medicilândia no ano de 2016. O desempenho dos algoritmos testados neste trabalho correspondeu às premissas formuladas ao longo do estudo.

A avaliação da qualidade das classificações a partir dos valores obtidos da análise do Índice Kappa e da Exatidão Global, assim como uma análise visual dos resultados gerados. Foi verificado que o classificador Máxima Verossimilhança obteve melhor acurácia apresentando valor de Índice Kappa de 0,920 e Exatidão Global de 96\%, do que o classificador de Distância Mínima e Distância Mahalanobis que obtiveram resultados de Índice Kappa de 0,842 e 0,845 e, Exatidão Global de 92\% respectivamente.

É importante destacar que todos os métodos testados apresentaram acurácias altas, consideradas excelentes classificações da cobertura do solo. A acurácia do produto dá um bom indício da qualidade do mapeamento explicitando a porcentagem de área mapeada de uma classe que corresponde a sua realidade.

Os resultados obtidos no trabalho demonstram que mesmo dispondo-se de recursos limitados, imagens de baixo custo, ampla disponibilidade e baixa resolução espacial, sistemas abertos e livres para processamento e integração das informações, é possível a obtenção de parâmetros para compor estudos prospectivos de fatores socioambientais de grande interesse, pois as informações obtidas dão subsídios a órgãos de planejamento territorial e ambiental.

\section{REFERÊNCIAS}


|Análise comparativa de métodos de classificação supervisionada aplicada ao mapeamento da cobertura do solo no município de Medicilândia, Pará|

|Jones Remo Barbosa Vale | Jamer Andrade da Costa | Jefferson Ferreira dos Santos | Elton Luis Silva da Silva | Artur Trindade Favacho|

ADLER-GOLDEN, S. M. et al. Atmospheric correction for short-wave spectral imagery based on MODTRAN4. SPIE Proceeding, Imaging Spectrometry, v. 3753, p. 61-69, 1999.

AMARAL, M. V. F. et al. Avaliação e comparação de métodos de classificação de imagens de satélites para o mapeamento de estádios de sucessão florestal. Revista Árvore, v. 33, n. 03, p. 575-582, 2009.

ANDERSON, G. P. et al. FLAASH and MODTRAN4: state-of-the-art atmospheric correction for hyperspectral data. In: AEROSPACE CONFERENCE, IEEE, Snowmass at Aspen, 1999. Proceedings... Snowmass at Aspen: IEEE, 1999. p. 177-181.

ANDRADE, A. C.; FRANCISCO, C. N.; ALMEIDA, C. M. Desempenho de classificadores paramétrico e não paramétrico na classificação da fisionomia vegetal. Revista Brasileira de Cartografia, Rio de Janeiro, n. 66/2, p. 349-363, 2014.

BERNARDI, H. V. F.; DZEDZEJ, M.; CARVALHO, L. M. T.; ACERBI JÚNIOR, F. W. Classificação digital do uso do solo comparando os métodos "pixel a pixel" e orientada ao objeto em imagem QuickBird. In: SIMPÓSIO BRASILEIRO DE SENSORIAMENTO REMOTO, 13., 2007, Florianópolis. Anais... São José dos Campos: INPE, 2007. p. 55955602.

BRITES, R. S. Verificação da exatidão em classificação de imagens digitais orbitais: efeitos de diferentes estratégias de amostragens e avaliação de índices de exatidão. 1996. 101 f. Tese (Doutorado em Ciência Florestal) - Universidade Federal de Viçosa, Viçosa, 1996.

BRITO, J. L. S.; PRUDENTE, T. D. Análise temporal do uso do solo e cobertura vegetal do município de Uberlândia/MG, utilizando imagens ETM, Landsat 7. Sociedade \& Natureza, Uberlândia, v. 17, n. 32, p. 37-46, 2005.

CAMARA, G. et al. SPRING: Integrating remote sensing and GIS by object-oriented data modeling. Computers \& Graphics, v. 20, n. 03, p. 395-403, 1996.

CAMPBELL, J. B. Introduction to Remote Sensing. New York: The Guilford Press, 1996.

COHEN, J. A. Coefficient of Agreement for Nominal Scales. Educational and Psychological Measurement, v. 20, n. 01, p. 37-46, 1960.

CONGALTON, R. G. A review of assessing the accuracy of classifications of remotely sensed data. Remote Sensing of Environment, v. 37, n. 01, p. 35-46, 1991.

COOLEY, T. et al. FLAASH, a MODTRAN4-based atmospheric correction algorithm, its application and validation. In: GEOSCIENCE AND REMOTE SENSING SYMPOSIUM, IEEE International (IGARSS), Toronto, 2002. Proceedings... Toronto: IEEE, 2002. p. 1414-1418.

CORREIA, V. R.; MONTEIRO, A, M, V.; CARVALHO, M. S.; WERNECK, G. L. Uma aplicação do sensoriamento remoto para a investigação de endemias urbanas. Caderno Saúde Pública, Rio de Janeiro, v. 23, n. 05, p. 1015-1028, 2007. 
|Análise comparativa de métodos de classificação supervisionada aplicada ao mapeamento da cobertura do solo no município de Medicilândia, Pará|

|Jones Remo Barbosa Vale | Jamer Andrade da Costa | Jefferson Ferreira dos Santos | Elton Luis Silva da Silva | Artur Trindade Favacho|

CRÓSTA, A. P. Processamento Digital de Imagens de Sensoriamento Remoto. 4. ed. Campinas: IG/UNICAMP, 2002.

FITZ, P. R. Cartografia Básica. 3. ed. São Paulo: Oficina de Textos, 2008.

FLORENZANO, T. G. Interpretação de Imagens. In: Di MAIO et al. (Org.). Sensoriamento Remoto. São Paulo: AEB, 2008.

FONSECA, L. M. G. Processamento Digital de Imagens. São José dos Campos: Instituto Nacional de Pesquisas Espaciais, 2002.

FVPP. Fundação Viver, Produzir e Preservar. Plano Territorial de Desenvolvimento Rural Sustentável: território da cidadania transamazônica Estado do Pará. Altamira: MDA, 2010.

IBGE. Instituto Brasileiro de Geografia e Estatística. Censo Demográfico de 2010. Rio de Janeiro: IBGE, 2010.

INPE. Instituto Nacional de Pesquisas Espaciais. Manuais: tutorial de geoprocessamento do SPRING. São José dos Campos: INPE, 2008.

JENSEN, J. R. Sensoriamento Remoto do ambiente: uma perspectiva em recursos terrestres. São José dos Campos: Parêntese, 2009.

LAMPRECHT, H. Silvicultura nos trópicos: ecossistemas florestais e respectivas espécies arbóreas: possibilidades e métodos de aproveitamento sustentado. Eschborn: Instituto de Silvicultura da Universidade de Göttingen, GTZ, 1990.

LANDIS, J. R.; KOCH, G. G. The measurement of observer agreement for categorical data. Biometrics, v. 33, n. 01, p. 159-174, 1977.

LILLESAND, T. M.; KIEFER, R. W.; CHIPMAN, J. W. Remote sensing and image interpretation. 6. ed. Hoboken, NJ: John Wiley \& Sons, 2008.

MENESES, P. R.; ALMEIDA, T. Introdução ao Processamento de Imagens de Sensoriamento Remoto. Brasília: UNB, 2012.

NOVO, E. M. L. M. Sensoriamento Remoto: princípios e aplicações. 4. ed. São Paulo: Blucher, 2010.

QUEIROZ, R. B.; RODRIGUES, A. G.; GÓMEZ, A. T. Redes Neurais: Um comparativo com Máxima Verossimilhança Gaussiana na Classificação de Imagens CBERS 1. In: WORKSHOP DE TECNOLOGIA DA INFORMAÇÃO APLICADA AO MEIO AMBIENTE, 2., 2004, Itajaí. Anais... Itajaí: CBComp, 2004. p. 746-749.

RIBEIRO, R. J. da C.; BAPTISTA, G. M. de M.; E. de S. B. Comparação dos métodos de classificação supervisionada de imagem Máxima Verossimilhança e Redes Neurais em ambiente urbano. In: SIMPÓSIO BRASILEIRO DE SENSORIAMENTO REMOTO, 13., 2007, Florianópolis. Anais... São José dos Campos: INPE, 2007. p. 5471-5478. 
|Análise comparativa de métodos de classificação supervisionada aplicada ao mapeamento da cobertura do solo no município de Medicilândia, Pará|

|Jones Remo Barbosa Vale | Jamer Andrade da Costa | Jefferson Ferreira dos Santos | Elton Luis Silva da Silva | Artur Trindade Favacho|

RICHARDS, J. A.; JIA, X. Remote Sensing Digital Image Analysis: an introduction. 4. ed. New York: Springer Verlag, 2006.

RODRIGUES, M. T. Comportamento de Sistemas de Informações Geográficas por meio de classificação supervisionada em diferentes bacias hidrográficas. 2015. $118 \mathrm{f}$. Tese (Doutorado em Agronomia) - Universidade Estadual Paulista, Botucatu/SP, 2015.

ROSA, R. Introdução ao Sensoriamento Remoto. 7. ed. Uberlândia: Ed. UFU, 2009.

VALENTE, A. M. Estudo da potencialidade de registro de indicação geográfica a produção de cacau no município de Medicilândia/PA. 2012. 120 f. Dissertação (Mestrado em Recursos Naturais e Desenvolvimento Local) - Universidade Federal do Pará, Belém, 2012.

VENTURIEIRI, A. Introdução às técnicas de Sensoriamento Remoto. Belém: UFPA, 2007.

VIEIRA JUNIOR, J. A. Análise comparativa dos métodos de classificação de imagem de alta resolução para mapeamento da cobertura do solo. 2011. $32 \mathrm{f}$. Monografia (Especialização em Geoprocessamento) - Universidade Federal de Minas Gerais, Belo Horizonte, 2011.

ZANETTI, J.; BRAGA, F. L. S.; DUARTE, D. C. O. Comparação dos métodos de classificação supervisionada de imagem máxima verossimilhança, distância euclidiana, paralelepípedo e redes neurais em imagens vant, utilizando o método de exatidão global, índice kappa e o tau. In: SIMPÓSIO BRASILEIRO DE GEOMÁTICA, 4., 2017, Presidente Prudente. Anais... Presidente Prudente: UNESP, 2017. p. 244-250. 